\title{
Effect of Aluminium Hydroxide on Thermal, Dynamic Mechanical and Dielectric Properties of Hexafluoropropylene- vinylidinefluoride Elastomeric Composites
}

\author{
Ajalesh Balachandran Nair ${ }^{* 1,2,3}$, Dhanya Vijayan ${ }^{1}$, Ayswarya E P ${ }^{1,3}$, Rani Joseph ${ }^{1}$ and Changwoon \\ $\mathrm{Nah}^{2}$ \\ ${ }^{1}$ Department of Polymer Science and Rubber Technology, Cochin University of Science \& Technology (CUSAT), \\ Kochi-682 022, India \\ ${ }^{2}$ BK21 Plus Haptic Polymer Composite Research Team, Department of Polymer-Nano Science and Technology, \\ Chonbuk National University (CBNU), Jeonju 561-756, Republic of Korea \\ ${ }^{3}$ Federal Institute of Science and Technology (FISAT), Hormis Nagar, Angamaly, Kerala, India \\ Email: *ajilesh4kannan@gmail.com
}

\begin{abstract}
Aluminium hydroxide (ATH) particles were incorporated at different loadings into fluorocarbon rubber (FKM), to study the effect of filler loading on the cure characteristics, mechanical properties, dynamic mechanical properties and thermal stability. The mechanical properties of FKM/ATH composites were better than medium thermal black filled vulcanizates. The storage modulus (E') of the composites was found to increase due to the enhancement in stiffness. The viscoelastic properties revealed that there is a strong interaction between the polymer and the filler. The dielectric permittivity, AC conductivity and absorption coefficient of the highly ATH loaded systems are much greater than the unfilled and lower systems.
\end{abstract}

Keywords: Elastomers, mechanical properties, thermal properties, dielectric properties.

\section{Introduction}

Polymer composites have an important role in electrical engineering in recent years. The application of polymeric materials in this field however requires special precautions because they can catch fire easily. In comparison to traditional inorganic materials such as glass, ceramics and mica, they offer considerable advantages including excellent insulation properties, low electric losses, ease of fabrication and processing. To be useful in electrical applications, the polymeric material should have good electric insulation characteristics, in addition to flame resistance[1]. The studies on flame-retarding polymeric materials have become indispensable since these materials are widely used. There are four factors affecting the process of combustion, which are oxygen, heat, flammable materials and thermal degradation[2].

Brominated flame retardants, which stop the thermal degradation of composites by reacting with polymers, are the most effective flame retardants in the market that are adopted for most engineering polymers[3]. However, halogenated flame retardants release toxic gases when they are subjected to high temperatures. With the proposal of the concept of environmental friendly flame retardants, some brominated flame retardants are replaced by halogen free flame retardants, particularly metallic hydroxide such as magnesium hydroxide[4], aluminium hydroxide[5] etc. In these metallic hydroxide flame retardants, aluminium hydroxide (ATH) is one of the most popular, safe, halogen free and smoke suppressants flame retardant. Other benefits include low material cost, elimination of heavy metal promoters (e.g. antimony oxide), and absence of toxic fume generation[6].

Over the past fifty years, fluoroelastomers (FKM) have benefited the world in several ways. Fluoroelastomer products are a family of specialty materials appreciated for their elastic behavior under comparatively harsh conditions[7]. These elastomers are largely used in seals and other fabricated components to afford barriers against a broad range of fluids under severe conditions. Majority of the fluoroelastomers products are utilized in automotive applications, mainly in fuel and high pressure sealing 
application. Amounts of fluoroelastomers consumed per vehicle are small compared to natural and synthetic rubber within the tires of a vehicle, but the fluoroelastomer parts are crucial for safety reason, reliable operation and environmental protection. Other application areas of fluoroelastomers include aerospace appliances, fluid power, chemical industry, oil field, semiconductors and high pressure seals for plasma coating[8]. It is a common tradition to incorporate some filler into the rubber matrix in order to obtain the ultimate properties out of it and fluoroelastomers are also not an exception. To improve their performance, various fillers have been examined, including carbon black[9], expanded graphite flakes[10] and recently nanofillers like layered silicates[11], carbon nanotube[12], polyhedral oligomeric silsesquioxane (POSS)[13], etc.

In this study, ATH filled composites based on FKM rubber were prepared. The effect of ATH loading on the cure, mechanical, dynamic mechanical and thermal properties of the composites was evaluated. The dielectric properties at microwave frequencies of the prepared composites were measured in the S-band (2-4 GHz) frequency using the cavity perturbation technique. The properties like dielectric permittivity, dielectric loss, conductivity, dielectric heating coefficient and absorption coefficient were evaluated. SEM studies were carried out to visualize the dispersion of ATH particles in the FKM matrix.

\section{$2 \quad$ Experimental}

\subsection{Composite Preparation}

Viton A401C, a fluoroelastomer containing bisphenol curatives with specific gravity of $1.82 \mathrm{~g} / \mathrm{cm}^{3}$ and Mooney viscosity 42 at $120^{\circ} \mathrm{C}$ was obtained from DuPont Dow Elastomers. Dioctylphthalate (DOP) was a commercial grade, supplied by Rubo-Synth impex Pvt. Ltd. Magnesium oxide was also a commercial grade calcined light magnesia with a specific gravity of $3.6 \mathrm{~g} / \mathrm{cm}^{3}$, supplied by Central Drug House Pvt. Ltd., Mumbai. MT black (N990) was supplied by Vajra rubber products, Thrissur. Aluminium hydroxide gel, dried and purified $\left(\mathrm{Al}_{2} \mathrm{O}_{3} \geqslant 47 \%, \mathrm{pH} \leqslant 10\right)$ was obtained from Merck Specialities Pvt. Ltd., Mumbai.

The composites were prepared in a laboratory size $(15 \mathrm{X} 33 \mathrm{~cm})$ two-roll mill at a friction ratio of 1 : 1.25 as per ASTM D 3184-89 (2001). The formulation for the preparation of composites is given in table 1. The ATH fillers were incorporated into FKM at various loadings (0, 10, 20, 30, 40 and 50 phr). The

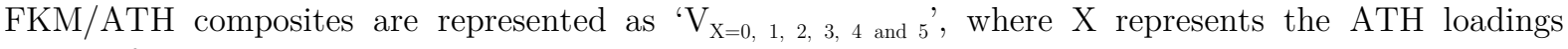
varying from 0 to $50 \mathrm{phr}$.

Table 1. Formulations used in the preparation of FKM/ATH composites

\begin{tabular}{lcccccc}
\hline Ingredients & $\mathrm{V} 0$ & $\mathrm{~V} 1$ & $\mathrm{~V} 2$ & $\mathrm{~V} 3$ & $\mathrm{~V} 4$ & $\mathrm{~V} 5$ \\
\hline FKM & 100 & 100 & 100 & 100 & 100 & 100 \\
ATH & - & 10 & 20 & 30 & 40 & 50 \\
$\mathrm{Ca}(\mathrm{OH}) 2$ & -6.0, & $\mathrm{MgO}-4.0$ & & & & \\
\hline
\end{tabular}

\subsection{Composite Characterization}

The cure characteristics of the mixes were determined using a Rubber Process Analyser RPA 2000 supplied by Alpha Technologies, USA, as per ASTM D 2084-01. Subsequently, the rubber compounds were vulcanized up to their respective optimum cure time at $150^{\circ} \mathrm{C}$ at $200 \mathrm{~kg} / \mathrm{cm}^{2}$. The mouldings were cooled quickly in water at the end of the curing cycle and stored in cool dark place for $24 \mathrm{~h}$ prior to physical testing.

The tensile properties were determined using dumbbell shaped specimens punched out from the vulcanized sheets. The measurements were carried out on a Shimadzu Universal testing machine (10 KN) with a grip separation of $40 \mathrm{~mm}$, using a crosshead speed of $500 \mathrm{~mm} / \mathrm{min}$ as per ASTM D 412 .

Thermogravimetric analysis of the samples was carried out in TGA Q-50 thermal analyzer (TA Instruments) under nitrogen atmosphere. The samples were heated from room temperature to $800^{\circ} \mathrm{C}$ at a 
heating rate of $20^{\circ} \mathrm{C} / \mathrm{min}$ and a nitrogen gas flow rate of $40-50 \mathrm{~cm}^{3} / \mathrm{min}$. The sample weight varied from 10-15 mg. The onset of degradation temperature, the temperature at which weight loss is maximum $\left(\mathrm{T}_{\max }\right)$, and residual weight were evaluated.

Dynamic mechanical analysis (DMA) was carried out on a DMA Q800 dynamic mechanical analyzer (TA instruments) using a tension film mode. Samples for DMA measurement were cut from the vulcanized sheets. All samples were tested from -80 to $40^{\circ} \mathrm{C}$ at a ramp rate of $3^{\circ} \mathrm{C} / \mathrm{min}$ and a frequency of $1 \mathrm{~Hz}$. Oscillating strain was set at $0.02 \%$ for all tests.

The microwave characteristics of the composites were studied using Agilent Performance Network Analyzer E8362 B. The measurements were carried at S-band (2-4 GHz). The microwave characteristics of the prepared composites were studied using cavity perturbation technique [14-18].

Scanning electron microscopic studies of the tensile fractured surfaces of the vulcanizates was done on an electron microscope (JEOL JS M840A).

\section{$3 \quad$ Results and Discussion}

\subsection{Cure Characteristics}

The crosslinking of fluoroelastomers is usually carried out at moderately elevated temperature. The fluoroelastomer composites used in this study have a two-stage curing process including a initial curing stage for optimum cure time at $150{ }^{\circ} \mathrm{C}$ and a post curing stage for $6 \mathrm{~h}$ at $160{ }^{\circ} \mathrm{C}$. Fig. 1 describes the improvement of torque against time at $150{ }^{\circ} \mathrm{C}$ of the FKM composites in the presence of ATH and curing parameters are tabulated in table 2 .

Fig. 1 shows that at higher loadings, $D_{\max }$ value increases with increase in ATH loading, due to the viscosity increase of the elastomer by the addition of filler. The maximum torque, $\mathrm{D}_{\max }$ increases with increase in ATH loading. The maximum torque, $\mathrm{D}_{\max }$, is an index of the extent of crosslinking reactions and represents the shear modulus of the fully vulcanized rubber at the vulcanization temperature. It is also a measure of the filler-polymer interaction. The minimum torque, $\mathrm{D}_{\text {min }}$; which is a measure of the viscosity of the compound, is found to increase with filler loading. $\mathrm{D}_{\min }$ can be considered as a measure of stiffness of the unvulcanized compound. The increase in viscosity with the addition of filler suggests a reduced mobility of the rubber chains caused by the incorporation of these fillers. Scorch time, $\mathrm{T}_{10}$; is the time required for the torque value to reach $10 \%$ of maximum torque. It is a measure of the scorch safety of the rubber compound. From table 2 , it is clear that the scorch time $\left(\mathrm{T}_{10}\right)$ decreases tremendously with the addition of ATH. This may be due to the participation of ATH filler in the curing cycle of FKM and also due to the heat of mixing resulting in the premature curing of the compounds. Generally, the cure characteristics depend on the filler properties such as nature of the filler, surface area, surface reactivity, aspect ratio and particle size. In general, a faster cure rate is obtained with fillers having lower surface area [19]. It is also interesting to note that in the present study a rather small amount of ATH (10 and $20 \mathrm{phr}$ ) reduced the $\mathrm{T}_{90}$ value abruptly (table 2). The $\mathrm{T}_{90}$ value of $20 \mathrm{phr}$ ATH filled composites has been decreased to $8.18 \mathrm{~min}$ from $26.02 \mathrm{~min}$ of the gum compound. But the further addition of filler increased $\mathrm{T}_{90}$ value due to agglomeration.

Table 2. Cure characteristics of FKM at varying ATH loading

\begin{tabular}{ccccc}
\hline $\begin{array}{c}\text { Sample } \\
\text { name }\end{array}$ & $\begin{array}{c}\text { Min. torque } \\
\left(\mathbf{D}_{\min }\right)\end{array}$ & $\begin{array}{c}\text { Max. torque } \\
\left(\mathbf{D}_{\max }\right)\end{array}$ & $\begin{array}{c}\text { Scorch time } \\
\left(\mathbf{T}_{\mathbf{1 0}}\right)\end{array}$ & $\begin{array}{c}\text { Cure time } \\
\left(\mathbf{T}_{\mathbf{9 0}}\right)\end{array}$ \\
\hline V0 & 0.44 & 5.76 & 13.1 & 26.02 \\
V1 & 0.66 & 7.33 & 4.28 & 9.85 \\
V2 & 0.73 & 4.54 & 1.18 & 8.18 \\
V3 & 1.52 & 5.47 & 1.10 & 10.8 \\
V4 & 1.98 & 5.56 & 1.10 & 14.05 \\
V5 & 2.80 & 6.65 & 0.86 & 16.51 \\
\hline
\end{tabular}




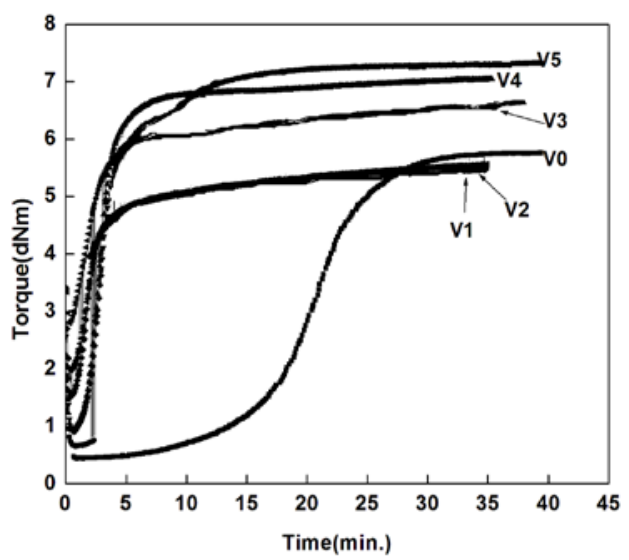

Figure 1. Cure rheographs of FKM composites

\subsection{Mechanical Properties}

It should be remembered here that unlike other rubbers, post curing (at $160{ }^{\circ} \mathrm{C}$ for $6 \mathrm{~h}$ ) of the FKM compounds is a very essential step to get desirable performance in the ultimate vulcanizate. The FKM compounds after post curing show better stress-strain properties. However, the change in molecular rearrangement during the post curing is still unknown. Efficient scavenging of hydrofluoric acid (HF) by $\mathrm{MgO}$ and $\mathrm{Ca}(\mathrm{OH})_{2}$ during post curing might be the reason for the formation of a stable crosslinked FKM matrix.

Representative stress-strain curves for the pure FKM and FKM at varying ATH loading are given in Fig. 2 and the tensile properties obtained from these curves are given in table 3 . The ultimate tensile properties reflect the reinforcing effect owing to the presence of ATH in FKM matrix. It is noted that with the inclusion of only $10 \mathrm{phr} \mathrm{ATH}$, the tensile strength and EB are increased to considerable extent compared to gum FKM. It is found that tensile strength increases from $9 \mathrm{MPa}$ to $14 \mathrm{MPa}(20 \mathrm{phr}$ ATH loading) while the maximum EB (554\%) is obtained at $30 \mathrm{phr}$ loading of the ATH filler. Therefore, a noteworthy enhancement in the magnitude of modulus at $100 \%$ elongation for the composites is observed as compared to unfilled compound. The improvement in tensile strength indicates homogeneous dispersion of the fillers and strong interfacial bonding (polar-polar interaction) between the fillers and the polymer matrix. Higher ATH loadings do not enhance the stress-strain properties due to the agglomeration of the filler particles.

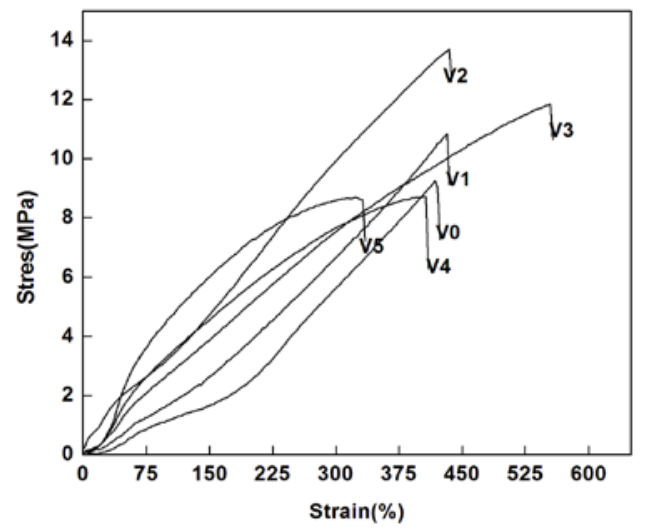

Figure 2. Stress-strain behavior of FKM at varying ATH loading 
Table 3. Tensile properties of FKM at varying ATH loading

\begin{tabular}{cccc}
\hline Name & Max. stress (MPa) & Max. strain (\%) & Modulus at 100\% \\
\hline V0 & 9 & 418 & 1.15 \\
V1 & 11 & 432 & 1.68 \\
V2 & 14 & 435 & 2.00 \\
V3 & 12 & 554 & 2.60 \\
V4 & 8 & 404 & 3.3 \\
V5 & 7 & 323 & 4.2 \\
\hline
\end{tabular}

\subsection{Mechanical Properties}

The stress-strain relationship was analyzed from the stress-strain behaviour illustrated by a phenomenological expression suggested by Mooney[20] and Rivlin and Saunders[21]:

$$
\sigma /\left(\lambda-\lambda^{-2}\right)=2\left(C_{1}+C_{2} \lambda^{-1}\right)
$$

where $\sigma$ is the applied stress, $\lambda$ is the extension ratio, and $\mathrm{C}_{1}, \mathrm{C}_{2}$ are the Mooney-Rivlin (MR) constants related to the network structure and the flexibility of the network chains. However, it does not explain the steep increase at large elongation. It is believed in many literatures that the upturn or steep increase in the stress-strain plot of rubbers is frequently attributed to the limiting polymer chain extensibility and also to the strain-induced crystallization ${ }^{[22,23]}$. Hence, both crystallizable and non-crystallizable rubbers can exhibit a steep increase of elastic force due to the limitation of polymer chain extensibility if the rupture is avoided. Furukawa et al.[22] proposed the modified Mooney-Rivlin equation based on the assumption of uniform stress rather than uniform strain as in original MR equation:

$$
\sigma=2\left(C_{1}+C_{2} / \lambda\right) F(\lambda)
$$

where $\sigma$ is the applied stress, $\mathrm{C}_{1}$ and $\mathrm{C}_{2}$ are the Mooney-Rivlin constants which are independent of the extension ratio $\lambda$, and the function of $\mathrm{F}(\lambda)$ can be denoted as

$$
F(\lambda)=\lambda-\left(1 / \lambda^{2}\right)+\left(\lambda_{m} / 3\right) *\left(\lambda / \lambda_{m}\right)^{3}+\ldots \ldots
$$

where $\lambda_{\mathrm{m}}$ is the maximum extension ratio, i.e., $\lambda$ at break point.

It is worth noting that at $\lambda<<\lambda_{m}$ the function $F(\lambda)$ approaches to $\lambda-1 / \lambda^{2}$, and eqn. 9 turns into the original MR equation. According to the modified MR equation, a plot of reduced stress (defined as ratio of $\sigma / F(\lambda)$ ) as a function of inverse extention ratio, $\lambda^{-1}$, should yield a linear curve, from which the values of $\mathrm{C}_{1}$ (intercept) and $\mathrm{C}_{2}$ (slope) can be readily obtained from the stress-strain curves. Similarly, according to the modified MR equation, the upturn $\left(1 / \lambda_{\text {up }}\right)$ values can be given by,

$$
(1 / \lambda)_{u p}^{3}=(2 / 3)\left(1 / \lambda_{m}{ }^{2}\right)\left(C_{1} / C_{2}\right)
$$

The values of $\mathrm{C}_{1}, \mathrm{C}_{2}$ and the quantitative value of upturn $\left(1 / \lambda_{\text {up }}\right)$ of the $\mathrm{FKM} / \mathrm{ATH}$ composites are summarized in table 4 . The constant $\mathrm{C}_{1}$ is an approximation to the high-deformation modulus, and is a direct measure of the degree of cross linking or an inverse measure of the molecular weight Mc of network strands between crosslinks. As expected, the degree of crosslinking is increased with the increase amount of ATH loading, as reported in table 4. In case of unfilled FKM, a small upturn at high strain can be noticed. This upturn $\left(1 / \lambda_{\text {up }}\right)$ in the modified MR plot may be attributed to the fact of strain-induced crystallization and limited chain extensibility.

The stress-strain curve for unfilled FKM exhibits a large increase in stress at higher deformations. FKM displays, due to its uniform microstructure, a very unique important characteristic, that is, the ability to crystallize under strain, a phenomenon known as strain-induced crystallization. This phenomenon is responsible for the large and abrupt increase in the reduced stress observed at higher deformation corresponding, in fact, to a self-toughening of the elastomer because the crystallites act as additional cross-links in the network. This process can be better visualized by using a Mooney-Rivlin representation, based on the so-called Mooney-Rivlin equation. The curves of the unfilled vulcanizate displays, at higher deformations, an upturn in the modulus ascribed to the strain-induced crystallization of polymer chains and is shown in Fig.3. For the composites filled with $10 \mathrm{phr}$ ATH, the upturn is still observed but it starts at a lower extension ratio than that of the unfilled sample. That means that the addition of ATH favors the crystallization process. The reduction in the strain at rupture for the other 
composites does not allow the observation of the tensile behaviour at high deformations. Unfortunately, the rupture properties are negatively affected by the ATH probably on account of the presence of some agglomerates which act as failure points and lead to a degradation of the mechanical properties of the materials.

A similar observation was observed by Hsu and Mark[24] when they used different cross-linker for FKM rubber. A linear plot shows the validity of the Mooney-Rivlin equation. The addition of only 20 phr ATH in FKM matrix causes drastic enhancement not only in the extent of upturn but also in $\mathrm{C}_{1}$ value. This means that ATH particles assist the strain induced alignment of FKM rubber chains at low strain. Identical phenomenon has also reported in the case of nanoclay filled NR system [25]. It has been pointed out that the presence of filler not only accelerates the strain-induced crystallization, but also increases the extent of strain-induced crystallinity compared to the unfilled compound or the compounds containing conventional fillers, like carbon black and silica. The superior dispersion of ATH particles in the FKM matrix enhances the polymer filler interaction to a large extent. Therefore, this large interfacial interaction favours the orientation of rubber chains and initiates crystallization at much lower strain.

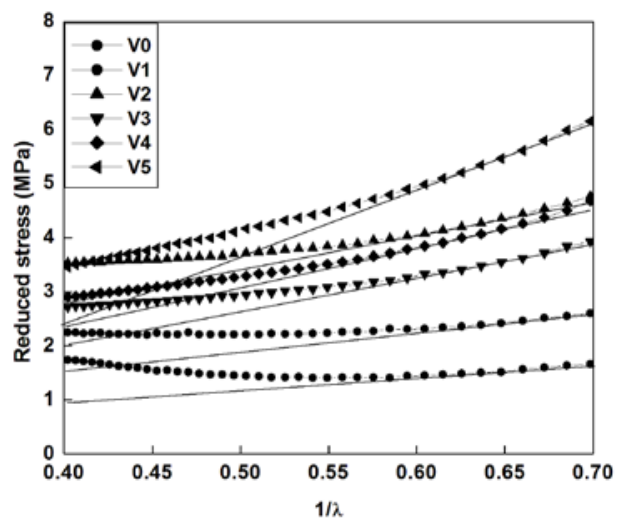

Figure 3. Mooney-Rivlin plot of the crosslinked FKM derived from the stress-strain plot

Table 4. Influence of ATH on the values of $\mathrm{C} 1$ and $\mathrm{C} 2$ with in FKM/ATH composites

\begin{tabular}{cccc}
\hline Sample Name & C1 & C2 & $\mathbf{1 / \boldsymbol { \lambda } _ { \text { up } }}$ \\
\hline V0 & 0.92 & 2.38 & 1.14 \\
V1 & 1.53 & 3.57 & 1.15 \\
V2 & 2.82 & 6.13 & 1.62 \\
V3 & 2.00 & 6.10 & 1.71 \\
V4 & 2.33 & 5.59 & 1.61 \\
V5 & 2.41 & 12.28 & 1.26 \\
\hline
\end{tabular}

\subsection{Thermal Stability of Composites}

The thermogram and derivative thermogram of ATH filled FKM composites is given in Fig. 4 (a) and (b) respectively. Thermal characteristics are given in table 5 . The dependence of degradation of the composites on ATH loading is better visualized in the DTG curve shown in Fig. 4 (b). The addition of ATH caused a remarkable decrease in the thermal stability of the elastomer, as is evident from TGA thermograms.

From table 5, gum FKM rubber vulcanizates exhibit maximum degradation $\left(\mathrm{T}_{\max }\right)$ at $498{ }^{\circ} \mathrm{C}$. And $20 \mathrm{phr}$ MT black loaded FKM exhibit $\mathrm{T}_{\max }$ at $502{ }^{\circ} \mathrm{C}$. All other ATH filled systems exhibit two $\mathrm{T}_{\max }\left(\mathrm{T}_{\max }{ }^{1}\right.$ and $\left.\mathrm{T}_{\max }{ }^{2}\right)$. The initial degradation is mainly due to the filler particles and the second degradation due to rubber. The maximum degradation temperature decreases and residue increases with increase in ATH loading. This may be due to the filler particle, which decomposed at elevated temperature and the decomposition products may catalyze the thermal decomposition of the elastomer. 

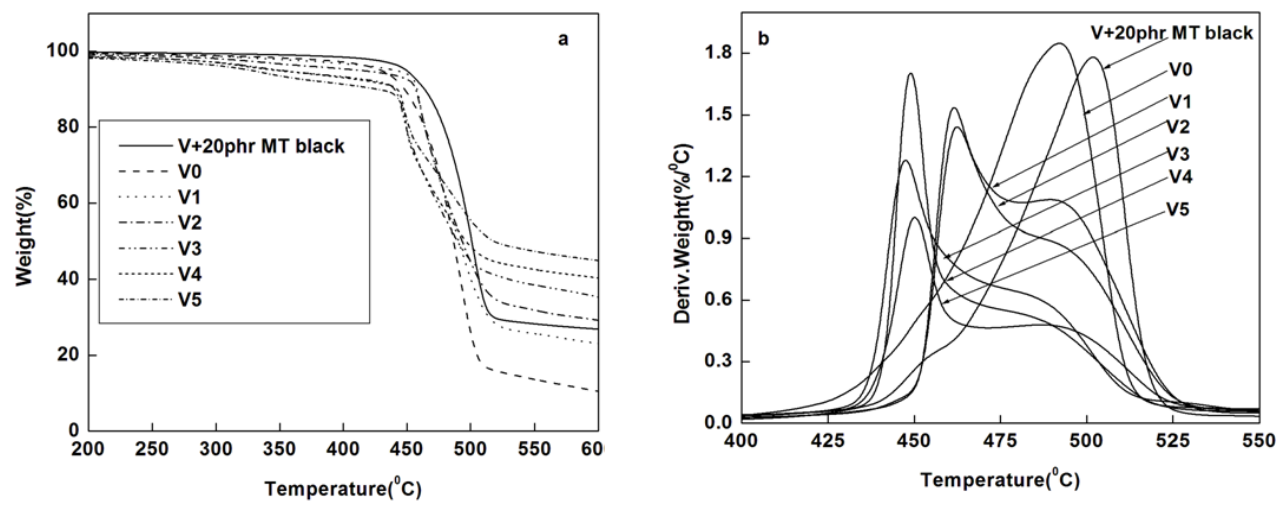

Figure 4. (a) Thermogram and (b) derivative thermogram of ATH filled FKM composites

Table 5. Thermal characteristics of ATH filled FKM composites

\begin{tabular}{ccccc}
\hline Sample name & Onset of degradation $\left(\mathbf{T}_{\mathbf{0}},{ }^{\circ} \mathbf{C}\right)$ & \multicolumn{2}{c}{$\begin{array}{c}\text { Max. degradation } \\
\left(\mathbf{T}_{\max },{ }^{\circ} \mathbf{C}\right)\end{array}$} & \multirow{2}{*}{ Residue (\%) } \\
\cline { 3 - 4 } & & $\mathbf{T}_{\max }{ }^{1}$ & $\mathbf{T}_{\max }{ }^{2}$ & \\
\hline V+20phr MT & 424 & - & 502 & 24 \\
V0 & 426 & - & 498 & 15 \\
V1 & 423 & 456 & 485 & 19 \\
V2 & 422 & 455 & 486 & 22 \\
V3 & 420 & 447 & 484 & 23 \\
V4 & 418 & 445 & 481 & 32 \\
V5 & 416 & 439 & 475 & 36 \\
\hline
\end{tabular}

\subsection{Dynamic Mechanical Analysis}

DMA measurements are often used to evaluate polymer stiffness under dynamic mode. The glass transition temperature, $\mathrm{T}_{\mathrm{g}}$ represents the temperature at which physical properties change drastically when the material transit from a hard glassy state to a rubbery state. Large segments of polymer chains start cooperative movement when the polymer reaches its glass transition temperature.

Dynamic mechanical properties were measured to examine the extent of filler-matrix interaction of the FKM/ATH composites. Fig. 5 shows the effect of ATH on storage modulus of the FKM composites as a function of temperature. From Fig. 5 , it is clear that the storage modulus (E') of the FKM/ATH composite with $20 \mathrm{phr}$ ATH loading was greater than the $\mathrm{E}^{\prime}$ of both pure FKM and FKM/ATH composites containing different amounts of ATH.

Fig. 6 shows the loss modulus (E") vs temperature curves of ATH filled FKM. 20 phr ATH loaded FKM shows higher loss modulus value when compared to MT black filled compounds. Gum vulcanizate shows lower E" compared to filled FKM vulcanizates. The Tan $\delta$ vs temperature curves of FKM/ATH composites is given in Fig. 7. Addition of the ATH results in a reduction of the maximum value tan $\delta$ up to $20 \mathrm{phr}$ loading with reduction in $\mathrm{Tg}$ is shown in table 6 . This is due to the typical confined relaxation behavior in polymer composites and also an increase of $\mathrm{Tg}$ is generally observed for covalently bonded interface interactions. For composites loaded with ATH that contains abundant reactive groups, the reaction between ATH and bisphenol curing agent may easily occur during the curing process. This interfacial reaction leads to stronger interfacial interactions with FKM rubber matrix. As a result, the ATH highly influences the molecular dynamics and cross-linking density of the FKM matrix, thereby increasing the storage modulus and reducing the $\mathrm{Tg}$ of the composites[26]. 


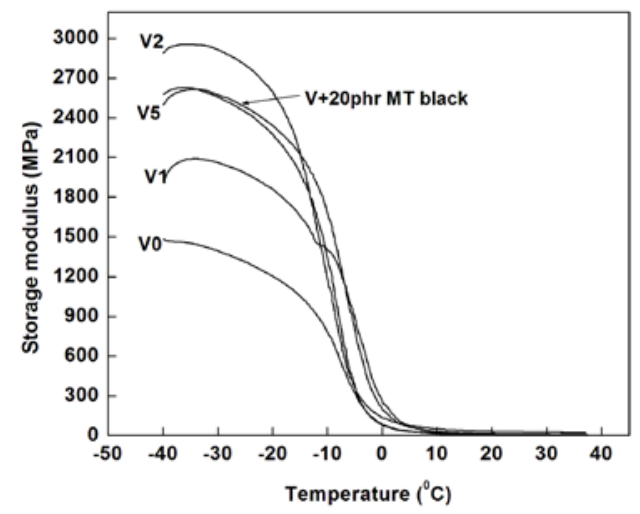

Figure 5. Storage modulus vs temperature curves of ATH filled FKM

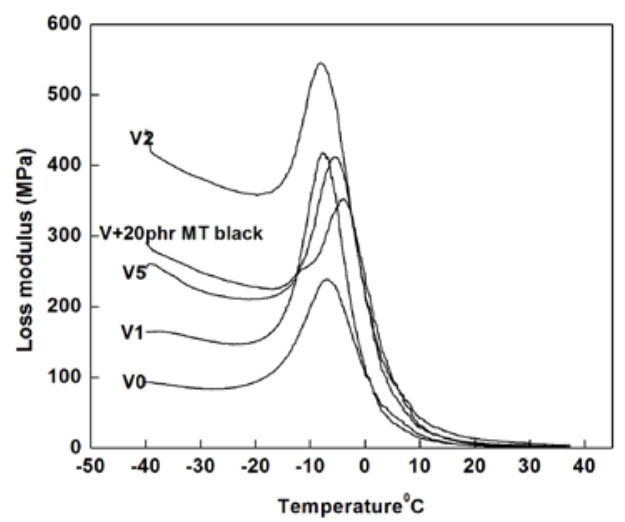

Figure 6. Loss modulus vs temperature curves of ATH filled FKM

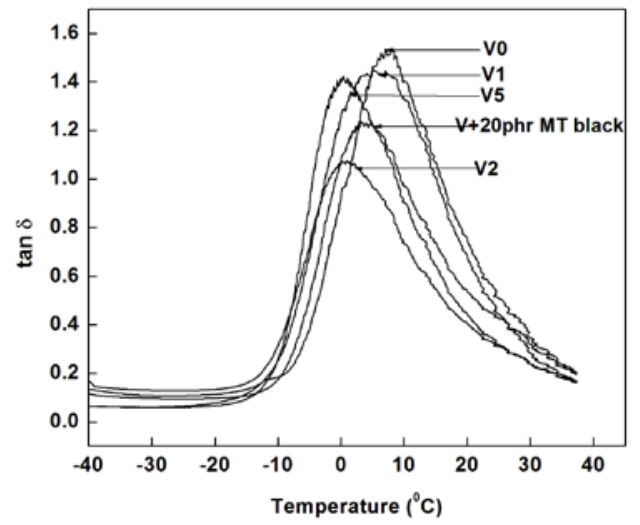

Figure 7. Tan $\delta$ vs temperature curves of FKM composites

Usually, due to the strong interfacial interactions between the rubber matrix and filler surface, the glass transition temperature $(\mathrm{Tg})$ is shifted to higher temperature. But it can be seen from table 6 that Tg of the FKM/ATH composites is shifted to lower temperature (from $+4{ }^{\circ} \mathrm{C}$ for gum to $-0.6{ }^{\circ} \mathrm{C}$ for 20 phr ATH loading), which may be due to the chain break down reaction of rubber matrix and ATH filler. Analogous observation has been recently reported in EPDM and NBR[27, 28] based composites. There are numerous other references stating identical observations $[29,30]$. Approximately $12{ }^{\circ} \mathrm{C}$ dwindle of $\mathrm{Tg}$ 
in case of silica-filled epoxy composites compared to unfilled gum compound was reported by Preghenella et al.[31]. Koerner et al. have also shown a decrease of $\mathrm{Tg}$ with increased amount clay mineral dispersion in the case of clay-epoxy nanocomposites[32] which has been attributed to two competitive effects such as rigid phase reinforcement, and destruction and plasticization of the network structure.

The relationship of the loss tangent values between the filled and the unfilled polymer matrix can be calculated using the following equation $[33,34]$ :

$$
\tan \delta=(\tan \delta m) /(1+1.5 B \varphi)
$$

where $\mathrm{B}$ is known as phenomenological interaction parameter which determines the interfacial interaction strength between the polymer matrix and filler surface. Larger the value of B, more will be the interaction between polymer and filler surface; $\varphi$ is the volume fraction of filler; $\tan \delta$ and $\tan \delta \mathrm{m}$ symbolize the loss tangent value of the filled and unfilled polymer matrix, respectively. The values of different interaction parameter have been calculated and tabulated in Table 6 . It can be noted that the interaction parameter is increased significantly with increasing amount of ATH up to $20 \mathrm{phr}$ and thereafter it declines. The value of B was even lower in case of V5 compared to V2, this may be due to the agglomeration of filler particles and hence showing inferior properties.

Table 6. Thermal characteristics of ATH filled FKM composites

\begin{tabular}{cccc}
\hline Sample name & $\tan \boldsymbol{\delta}_{\max }$ & $\mathbf{T}_{\mathbf{g}}$ from $\tan \boldsymbol{\delta}\left({ }^{\circ} \mathbf{C}\right)$ & Interaction parameter $(\mathbf{B})$ \\
\hline $\mathrm{V} 0$ & 1.53 & 4.3 & - \\
$\mathrm{V} 1$ & 1.44 & 4.2 & 0.22 \\
$\mathrm{~V} 2$ & 1.07 & -0.6 & 6.56 \\
$\mathrm{~V} 5$ & 1.42 & -1.7 & 3.94 \\
$\mathrm{~V}+20$ phr MT & 1.23 & 0.9 & 3.46 \\
\hline
\end{tabular}

\subsection{Dielectric Properties of the Composites}

The microwave characteristics of the composites were studied using cavity perturbation technique. The dependence of the imaginary part of the complex dielectric permittivity (dielectric losses) on the amount of the ATH filler and the frequency is shown in Fig. 8. The dielectric loss increases with the increasing content of ATH. The increase is the lowest for the least filled sample while the highest increase is observed for the sample filled with $50 \mathrm{phr}$ of ATH. The samples could be divided into three groups: in the first group is the non filled sample with the lowest dielectric constant value; to the second group belong the composites comprising 10, 20, 30 and $40 \mathrm{phr}$ of ATH having very close dielectric loss values; the composite filled with $50 \mathrm{phr}$ of ATH is in the third group which dielectric loss value is the highest. Obviously, filling FKM rubber with a significant amount of ATH (e.g., 50 phr) could be used to obtain FKM rubber composites possessing considerable dielectric loss values. The grouping of the composites (observed in the case of the dielectric permittivity as well) might be related to reaching and passing the percolation threshold, and to the formation of conductive paths. The statement is based on the comparison dependences of the relative dielectric permittivity on filler content and the mechanism of dielectric loss occurrence[35] related mostly to the nature of dielectric polarization.

With the increase of ATH loading, there is no significant variation in the dielectric losses, but at 45 phr ATH loading there is an increase in the loss factor. The dielectric loss of a composite is affected by extrinsic factors such as porosity, microstructure, moisture content, and interface between the polymer and the filler. A dense composite with low moisture content is needed for obtaining a low loss composite. With increase in filler volume fractions the space charge getting accumulated in the interfacial area increases, leading to an increase in dielectric loss. However, this interfacial effect is effective only at low frequencies[36].

The microwave conductivity is a direct function of dielectric loss and hence the Fig. 9, showing the variation of the $\mathrm{AC}$ conductivity $(\mathrm{S} / \mathrm{m})$ of composites. Conductivity of the matrix at lowest loading of filler is affected by three parameters viz. the intrinsic conductivity of the filler, the shape of the filler and also the surface tension of the matrix and filler[37]. Maximum conductivity $0.05 \mathrm{~S} / \mathrm{m}$ is obtained for higher ATH loading at $2.972 \mathrm{GHz}$. 


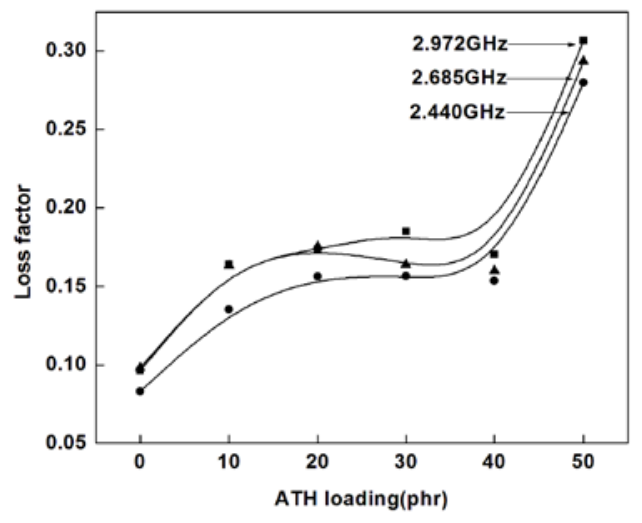

Figure 8. Variation of dielectric loss with ATH loading of FKM composites

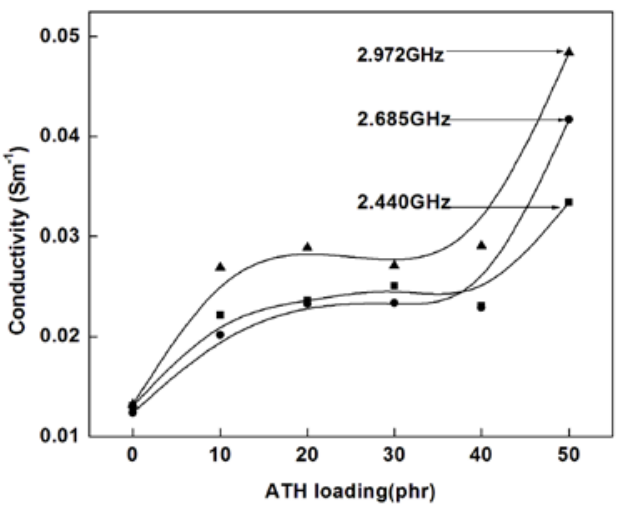

Figure 9. Variation of conductivity with ATH loading of FKM composites

The dielectric relaxation and polarization processes in these copolymers are still not clearly understood. The addition of inorganic materials, the chain polar segment motion in copolymer system occurs at a relatively low frequency range. The influence of the frequency and amount of the second filler is significantly pronounced in this frequency range. The polarization mechanism operating in the giga hertz $(\mathrm{GHz})$ frequency is purely electronic or orientational with relaxation times smaller than the time period of the applied signals. Interfacial polarization, which is the basic reason for the dispersion in dielectric permittivity at radio frequency region, has no role to play in microwave frequencies as it does not produce dispersion in dielectric permittivity because of its much smaller relaxation time. But dielectric permittivity is found to increase with the increase of phr of ATH platelets in the composite as it is evident from Fig. 10. This phenomenon of increase in dielectric permittivity with the increase in filler concentration can be attributed to the enhancement of electrical conductivity of the composites. Fig. 10 shows the change in dielectric constant of FKM rubber measured at 2.440, 2.685 and $2.972 \mathrm{GHz}$, with various ATH loading. It can be seen that the dielectric constant increases with increasing ATH loading and also with frequency. In a copolymer system, the CF2 dipoles are combined together by strong covalent bonds, and so, the orientation changes in the dipole moments require cooperative motion of the neighboring CF2 groups through the large-scale trans-gauche conformation change[38].

The tendencies of the changes in dielectric constant with filler content in Fig. 10 are analogous to those observed in the case of dielectric loss. The dielectric permittivity of the composites is also affected by a number of factors such as the porosity, size and shape of the filler particles, interface between the components and the effective dipole moment of the composites[39]. At lower loadings, since the filler is a minor dispersed phase, the major contribution to the dielectric response comes from the continuous rubber matrix. As the filler loading increases the filler particles form continuous 
networks and the dipole-dipole interaction increases. Consequently there will be a rise in dielectric permittivity of the composite[40].

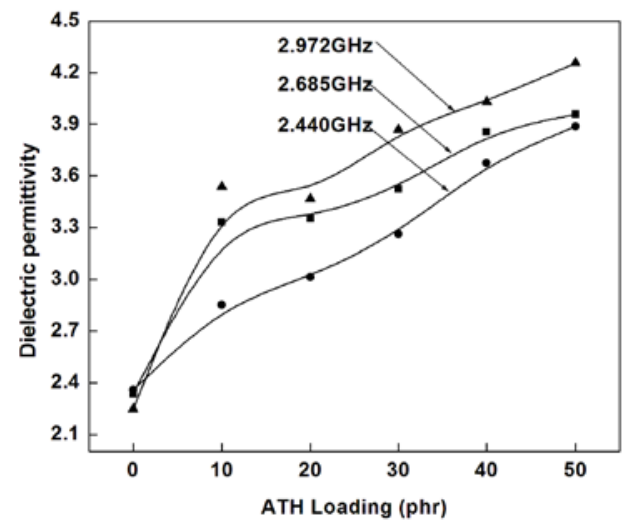

Figure 10. Variation of dielectric permittivity with ATH loading of FKM composites

Fig. 11 shows the variation of dielectric heating coefficient $(\mathrm{J})$ with frequency and with loading. It is observed that the heating coefficient decreases with frequency and also with filler loading. In the present study ' $\mathrm{J}$ ' value is found to be the lowest for $50 \mathrm{phr}$ ATH loaded FKM at $2.972 \mathrm{GHz}$ frequency. At 2.972 $\mathrm{GHz}$ the heating coefficient of gum vulcanizate is 10 while at 50 phr loading it is as low as 3.

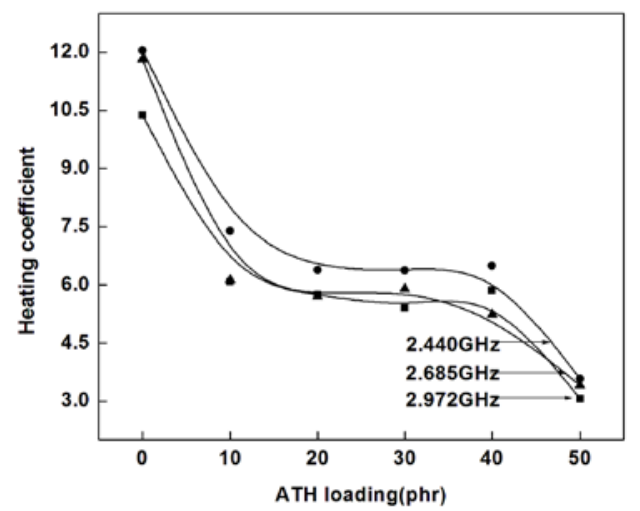

Figure 11. Variation of heating coefficient with ATH loading of FKM composites

The variation of absorption coefficient with ATH filler loading is same as that for AC conductivity in Fig. 12. It is clear that the absorption coefficient increases with increase in filler loading and maximum absorption coefficient value is obtained for 50 phr ATH loaded FKM rubber at $2.972 \mathrm{GHz}$. From Fig. 13 it is clear that the lowest value of skin depth is for the rubber containing 50 phr ATH loading at $2.972 \mathrm{GHz}$ frequency.

\subsection{Scanning Electron Microscopy}

Generally, the dispersion state of the fillers in a polymer matrix is one of the decisive factors in determining the ultimate properties of composites. Homogeneous dispersion of filler leads to high mechanical properties of the resulting composites. On the contrary, the aggregated fillers in the polymer matrix act as the stress-concentration points, leading to deterioration of mechanical properties. Fig. 14 shows the state and degree of dispersion of the ATH particles into the FKM matrix. It can be seen in Fig. 14 (a), that ATH particles are well dispersed in the FKM matrix for the sample containing $20 \mathrm{phr}$ ATH loading. As the concentration of ATH increases the dispersion of the filler becomes hindered. Large particles are embedded in the FKM matrixes which act as stress concentration points. It can also be observed from Fig. 14 (b), that ATH particles are forming a local filler-filler network in the rubber 
matrix and due to the existence of such clusters, the 'Payne effect' has been found to be pronounced in these systems. This is in good agreement with the observed stress-strain properties.

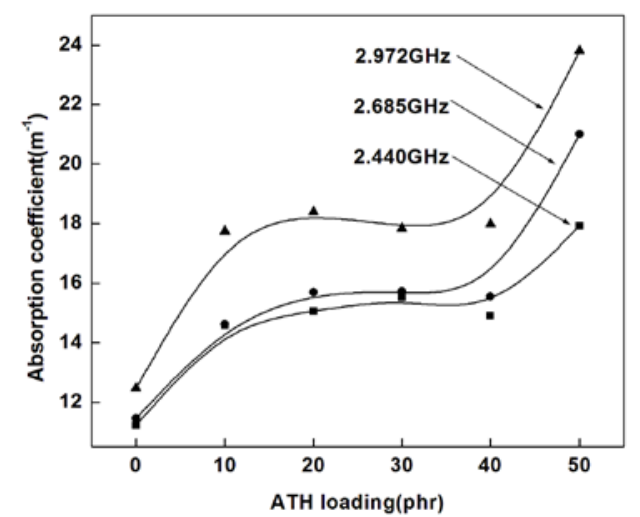

Figure 12. Variation of absorption coefficient with ATH loading of FKM composites

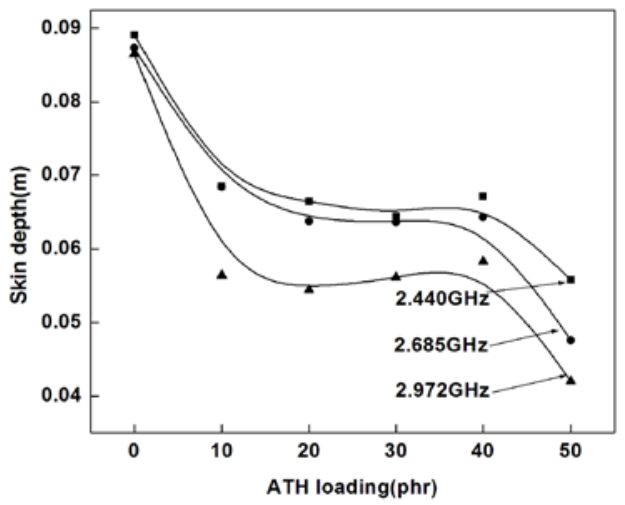

Figure 13. Variation of skin depth with ATH loading of FKM composites

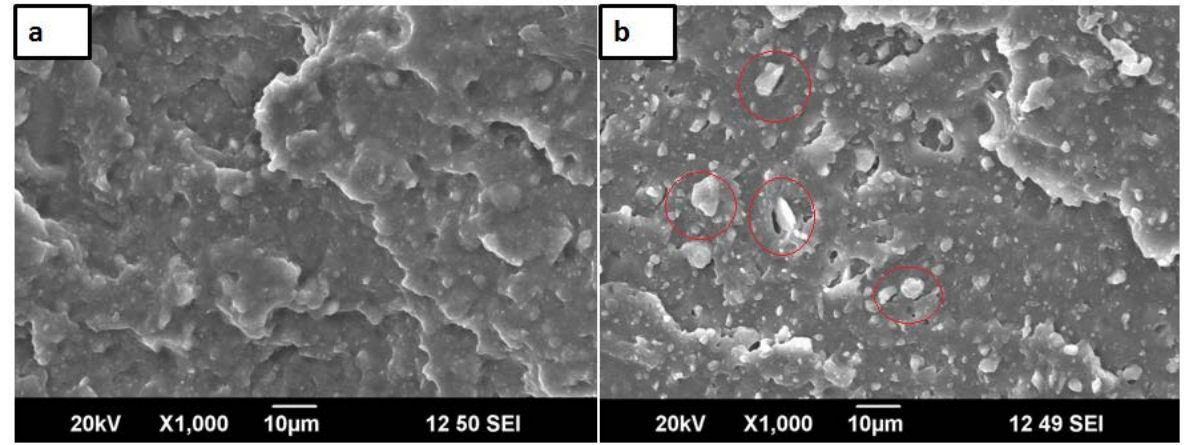

Figure 14. SEM photographs of tensile fractured surfaces of (a) 20 phr ATH and (b) 50 phr ATH filled FKM composites 


\section{Conclusions}

Rate of curing increases with increase in concentration of ATH in FKM rubber. Tensile properties increase by the addition of ATH to FKM. The addition of ATH tremendously decreases the optimum cure time. The composites with 20 phr ATH loading show better mechanical properties and storage modulus. The degree of improvement depends on their interactions with the elastomer matrix and their effects on elastomer vulcanization. The thermal degradation stability of FKM rubber is affected with the addition of ATH. Storage modulus increased with the addition of ATH and reached a maximum and then decreases. The dielectric permittivity and loss of the composites increase with increase in frequency and also with ATH concentration. The microwave conductivity of all the composites is highly dependent upon the frequency and the percolation threshold is observed at high ATH loading. The dielectric heating coefficient is found to be minimum for higher filler loading. The absorption coefficient is high and the skin depth or the penetration depth is low for samples with high ATH loading. Morphology of fracture surfaces shows better state of dispersion of particles and it is in good agreement with the variation in tensile properties.

Acknowledgements: This work was partly supported by the BK21 Plus program from the National Research Foundation (NRF) of South Korea.

\section{References}

1. A. Celzard, J.F. Mareche, G. Furdin, Puricelli S, "Electrical conductivity of anisotropic expanded graphite-based monoliths," J Phys D: Appl. Phys, vol. 33, pp. 3094-3101, 2000.

2. W. Zheng, S.C.Wong, H.J. Sue, "Transport behavior of PMMA/expanded graphite nanocomposites," Polymer, vol. 73, pp. 6767-6773, 2002.

3. D.S. Saunders, S.C. Galea, G. K. Deirmendjian, "Development of fatigue damage around fastener holes in thick graphite/epoxy composite laminates," Composite, vol. 24, pp. 309-321, 1993.

4. Y.A. Ezquerra, M. Kulescza, F. J. Alta-Calleja, "Electrical transport in polyethylene-graphite composite materials,". Synth Met, vol. 41-43, pp. 915-920, 1991.

5. G. Pinto and A. Jimenez-Martin, "Conducting aluminum-filled nylon 6 composites," Polym Compos, vol. 22, pp. 65-70,2001.

6. I .M. De Rosa, A. Dinescu, F. Sarasini, M.S. Sarto and A. Tamburrano, "Effect of carbon fibers and MWCNTs on microwave absorbing properties of polyester composites containing nickelcoated carbon fibers," Compos Sci \& Technol, vol. 70, pp. 102-109, 2010.

7. A.S. Sirqueira and B.G. Soares, "The Effect of Functionalized Ethylene Propylene Diene

Rubber (EPDM) on the Kinetics of Sulfur Vulcanization of Normal Rubber/EPDM Blends," Macromol Mater Eng, vol. 292, pp. 62-69, 2007.

8. Weili Wu and Chen Dajun, "Thermal and mechanical properties of dough modeling compound reinforced ethylene propylene diene monomer/silicon rubber composites," Polym Compos, vol. 27, pp. 621-626, 2006.

9. V. Deniz, B. Karaagac and N. Ceyhan, "Thermal stability of butyl/EPDM/neoprene based rubber compounds," J Appl Polym Sci, vol. 103, pp. 557-563, 2007.

10. A.B. Nair, P. Kurian and R. Joseph, "Effect of Expanded Graphite on thermal, mechanical and dielectric properties of Ethylene-Propylene-DieneTerpolymer/Hexafluoropropylene-vinylidinefluorideDipolymer rubber blends, " Euro Polym J, vol. 49, pp. 247-260, 2013.

11. M.A. Kader and A.K.Bhowmick, "Acrylic Rubber-Fluorocarbon Rubber Miscible Blends: Effect of Curatives and Fillers on Cure, Mechanical, Aging and Swelling Properties," J Appl Polym Sci, vol. 89, pp. 1442-1452, 2003.

12. B. Boutevin; G. Caporiccio; F.G. Pietrasanta and A. Ratsimihety, "Poly-silafluoro alkylene oligosiloxanes: a class of fluoroelastomers with low glass transition temperature, " J Fluorine Chem, vol. 124, pp. 131-138, 2003.

13. M. Maiti and A. Bhowmick, "Structure and properties of some novel fluoroelastomer/clay nanocomposites with special reference to their interaction," J Polym Sci Part B Polym Phys, vol. 44, pp. 162-176, 2006.

14. K. Kupfer, A. Kraszewski and R. Knoochel, "Cavity perturbation techniques for measuring dielectric parameters of water and other allied liquids," In Sensors Update, Wiley-VCH: Weinheim; 2000. 
15. C. C. Ku and R. Liepins, "Electrical Properties of Polymers: Chemical Principles, " Hansen Publishers, Munich; 1987.

16. T.A Ezquerra, F. Kremmer and Wegner, "Dielectric properties of heterogeneous materials: Progress in electromagnetic research," Elsevier, New York; 1992.

17. L.S. Bradford and M. H. Carpentier, "The Microwave Engineering Hand Book," Chapman \& Hall, London; 1993.

18. C.W. Stephen and H. L. Frederic, "Microwaves Made Simple: Principles and Applications," United States Book crafters: Chelsea; 1985.

19. M. Wagner, "Reinforcing silicas and silicates," Rubber ChemTechnol, vol. 49, pp. 703-774, 1976.

20. M. Mooney, "A theory of large elastic deformation," J Appl Phys, vol. 11(9) , pp. 582-592, 1940.

21. R.S. Rivlin and D.W. Saunders, "Large elastic deformation of isotropic materials. VII. Experiments on the deformation of rubber," Phil Trans Roy SocLond, A243 (865) , pp. 251-88, 1951.

22. J. Furukawa, Y. Onouchi, S. Inagaki and Okamoto H. "Rubber elasticity at very large elongation," Polym Bull, vol. 6 (7), pp. 381-7, 1981.

23. S. Pradhan, F.R.Costa, U. Wagenknecht, D. Jehnichen, A.K. Bhowmick and G. Heinrich, "Elastomer/LDH nanocomposites: synthesis and studies on nanoparticle dispersion, mechanical properties and interfacial adhesion," Eur Polym J, vol. 44(10), pp. 3122-32, 2008.

24. Y.H. Hsu and J.E. Mark, "Effects of strain-induced crystallization on the elastic and thermoelastic properties of some fluroelastomers," Polym Eng Sci, vol. 27, pp. 1203-8, 1987.

25. S. Joly, G. Garnaud, R. Ollitrault, L. Bokobza and J. E. Mark, "Organically modified layered silicates as reinforcing fillers for natural rubber," Chem Mater, vol. 14(10) , pp. 4202-8, 2002.

26. A. Das, K.W. Stokelhuber and G. Heinrich, "Influence of layered silicate on the self-crosslinking of polychloroprene and carboxylated nitrile rubber," Macromol Chem Phys, vol. 210(2), pp. 189-99, 2009.

27. A. Das, R. Jurk, K.W. Stoekelhuber and G. Heinrich, "Effect of vulcanization ingredients on the intercalationexfoliation process of layered silicate in an acrylonitrile butadiene rubber matrix," Macromol Mater Eng, vol. 293(6) , pp. 479-90, 2008.

28. P. Pasbakhsh, H. Ismail, M.N. Ahmad Fauzi and A.A. Bakar, "EPDM/modified halloysite nanocomposites," Appl Clay Sci, vol. 48(3), pp. 405-13, 2010.

29. X. Liu and Q. Wu, "PP/clay nanocomposites prepared by grafting-melt intercalation," Polymer, vol. 42(25), pp. 10013-9,2001.

30. J.S. Shelley, P.T. Mather and K.L. De Vries, "Reinforcement and environmental degradation of nylon-6/clay nanocomposites," Polymer, vol. 42(13) , pp. 5849-58, 2001.

31. M. Preghenella, A. Pegoretti and C.Migliaresi, "Thermo-mechanical characterization of fumed silica-epoxy nanocomposites," Polymer, vol. 46(26) , pp. 12065-72, 2005.

32. H. Koerner, D. Misra, A. Tan, L. Drummy, P. Mirau and R. Vaia, "Montmorillonite-thermoset nanocomposites via cryocompounding," Polymer, vol. 47(10), pp. 3426-35, 2006.

33. K.D. Ziegel and Romanov A, "Modulus reinforcement in elastomer composites. I. Inorganic fillers," J Appl Polym Sci, vol. 17(4), pp. 1119-1131, 1973.

34. S. J. He, Y.Q. Wang, Y.P. Feng, Q.S. Liu and Zhang L.Q, "The preparation of an elastomer/silicate layer nanocompound with an exfoliated structure and a strong ionic interfacial interaction by utilizing an elastomer latex containing pyridine groups," Nanotechnology, vol. 21(11) , pp. 5601-5608, 2010.

35. W. Niedermeier, "Degussa," Technical Reports TR 832.

36. H. Smaoui, L. E. L. Mir, H. Guermazi, S. Agnel and A. Toureille, "Study of dielectric relaxations in zinc oxideepoxy resin nanocomposites," J Alloys Comp, vol. 477, pp. 316-321, 2009.

37. T.A. Skotheim, "Handbook of conducting polymers," Vols 1 and 2. Marcel Dekker, New York; 1986.

38. K. Tashiro, "Ferroelectric Polymers: Chemistry, Physics, and Applications," Nalwa, H., Ed.; Marcel Dekker, New York; 1995

39. Y.C. Chen, H.C. Lin and Y.D. Lee, "Effect of filler content and size on the properties of PTFE/SiO2 composites," J Polym Res, vol. 10, pp. 247-258, 2003.

40. D.H. Kuo, C.C. Chang, T.Y. Su, W.K. Wang and B.Y. Lin, "Dielectric properties of three ceramic epoxy composites," Mater Chem Phys, vol. 85, pp. 201-206, 2004. 